\title{
Osteochondral defects: present situation and tissue engineering approaches
}

\author{
J. F. Mano ${ }^{1,2 *}$ and R. L. Reis ${ }^{1,2}$ \\ ${ }^{1}$ Biomaterials, Biodegradables and Biomimetics (3Bs) Research Group, Department of Polymer Engineering, University of Minho, Braga, \\ Portugal \\ ${ }^{2}$ Institute for Biotechnology and Bioengineering (IBB), PT Government-Associated Laboratory, Braga, Portugal
}

\begin{abstract}
Articular cartilage is often damaged due to trauma or degenerative diseases, resulting in severe pain and disability. Most clinical approaches have been shown to have limited capacity to treat cartilage lesions. Tissue engineering (TE) has been proposed as an alternative strategy to repair cartilage. Cartilage defects often penetrate to the subchondral bone, or full-thickness defects are also produced in some therapeutic procedures. Therefore, in TE strategies one should also consider the need for a simultaneous regeneration of both cartilage and subchondral bone in situations where osteochondral defects are present, or to provide an enhanced support for the cartilage hybrid construct. In this review, different concepts related to TE in osteochondral regeneration will be discussed. The focus is on the need to produce new biphasic scaffolds that will provide differentiated and adequate conditions for guiding the growth of the two tissues, satisfying their different biological and functional requirements. Copyright $\odot 2007$ John Wiley \& Sons, Ltd.
\end{abstract}

Received 16 May 2007; Accepted 13 June 2007

Keywords Tissue engineering; bi-layer scaffolds; regenerative medicine; osteochondral regeneration

\section{Introduction}

Articular cartilage injuries occur frequently as a result of trauma, tumour or osteoarthritis (OA). OA is the most prevalent disorder of the musculoskeletal system, affecting about $10 \%$ of the US population older than 30 , and most of the people over the age of 65 , with total direct costs estimated at $\$ 28.6$ billion/year (Felson and Zhang, 1998). Besides cartilage, OA also involves the synovium, joint capsule and subchondral bone. It is not yet completely clear why the different joints are not affected equally by this degenerative joint disease; this issue has been discussed recently by Kuettner and Cole (2005). However, the main pathological features of this disease are known and thought to develop as a result of destruction of cartilage matrix, leading to a progressive loss in joint function, together with the

*Correspondence to: J. F. Mano, Biomaterials, Biodegradables and Biomimetics (3Bs) Research Group, Department of Polymer Engineering, University of Minho, Campus de Gualtar, 4710057 Braga, Portugal: www.3bs.uminho.pt.

E-mail: jmano@dep.uminho.pt destabilization of supramolecular structures, including the collagen network, and changes in the expression profile of matrix molecules (Aigner and McKenna, 2002).

Articular cartilage lesions are typically irreversible, due to the unique features of this tissue (Temenoff and Mikos, 2000), including its avascular nature and consequent lack of access to a pool of potential reparative cells and humoral factors. Also, cartilage has a low cell:matrix ratio, and mature chondrocytes have a relatively low metabolic activity that limits any considerable capacity of remodelling (Hunziker, 2002; Pacifici et al., 2000). In cases where the lesions do not penetrate to the subchondral bone, the pluripotent progenitor cells from the bone marrow cannot be recruited and the repair will be limited. On the other hand, full-thickness (osteochondral) defects go through the subchondral bone, accessing the bone marrow cells, including mesenchymal stem cells (Redman et al., 2005) and also growth factors and cytokines. However, the repair response typically leads to the formation of fibrocartilage in the defect void (Shapiro et al., 1993), which is a poor substitute for articular cartilage, and a degeneration of both repaired and adjacent native tissues will be often observed after 
long-term follow-up (Buckwalter, 1998; Dounchis et al., 2000; Shortkroff et al., 1996).

Current treatments of articular cartilage have included: (a) the creation of a full-thickness defect by abrasion or drilling, to access to the migration of progenitor cells (Angel et al., 2003; Shapiro et al., 1993); (b) arthroscopic lavage and debridement, which eliminates debris from the joint space or joint surface, alleviating pain (Jackson et al., 2003; Shannon et al., 2001) (c) autograft procedures, such as 'mosaicplasty' (Hangody et al., 1998; Kish and Hangody, 2004) or osteochondral autograft transfer system (Attmanspacher et al., 2000), where osteochondral cylindrical plugs are removed from a joint area of minor load, such as the femoral trochlear groove, and press-fitted into pre-drilled holes at the defect site (van der Kooy and Weiss, 2000); (d) periosteal and perichondrial transplantation to full-thickness cartilage defects (Carranza-Bencano et al., 1999; O’Driscoll, 1998), aimed at introducing undifferentiated periosteal cells into the environments, leading to a source of chondrocytes; (e) autologous cell transplantation (chondrocytes or undifferentiated cells), previously expanded in vitro and reinjected under an autologous periosteal flap, sutured on the cartilage defect (Brittberg, 1999; Brittberg et al., 1994; Gillogly et al., 1998).

Each of the above-mentioned treatments have been shown to have limited success, as they are deficient and inconsistent in long-term repair; moreover, they also exhibit undesirable side effects and the treatments are usually limited to small lesions, making the overall outcome generally inadequate (Frenkel and Cesare, 2004; Hunziker, 2000, 2002; Newman, 1998; Redman et al., 2005). In fact, tissue transplantation inflicts further tissue destruction before any therapeutic effect can be achieved that is not guaranteed, as graft delamination and endochondral ossification are frequently found; moreover, drilling or surgical abrasion produces mainly fibrocartilage at the defect site, which often deteriorates with time.

Tissue engineering (TE) has emerged as a new multidisciplinary field, that joins the latest developments in cell/molecular biology, materials science and engineering, chemistry and medical sciences towards the development of hybrid substitutes (combining biodegradable supports, cells and signalling molecules, such as growth factors) aimed at restoring tissue or organs functions, using the natural signalling pathways and components of the organism (Langer et al., 1993). Accumulating results have shown that TE-based strategies have potential to be used in the regeneration of a series of tissues and organs (Atala, 2007) and are especially adequate for the regeneration of articular cartilage, due to its own limited repair capacity. Many studies have been published in this context (Glowacki, 2000; Grande et al., 1999; Temenoff and Mikos, 2000; Woodfield et al., 2002); however, most of this work has reported solutions for the regeneration of cartilage alone. In some situations there is the need to consider the use of osteochondral implants containing both replacement cartilage and subchondral bone.
In the case of full-thickness defects, it would be desirable to use biphasic constructs, which could satisfy the mechanical and biological requirements of both tissues. Even in partial-thickness (chondral) defects, the use of single scaffolds intended to regenerate cartilage may not be effective, as it is difficult to integrate the implant with the surrounding tissue. In that situation, a strategy could consist of creating a full-thickness defect and a posterior implantation of an osteochondral implant; this will help to anchor the graft into the defect since, as commented by Schaefer et al. (2000), a bone-to-bone interface integrates better and faster than a cartilage-to-cartilage interface.

A critical requirement of cartilage $\mathrm{TE}$ is the correct choice of the materials and the design of the scaffold structure. Even for a single tissue, the 'ideal scaffold' does not yet exist, and much more investigative work is needed on different materials combinations, the effect of porosity (porosity content, pore size distribution and interconnectivity), adequate cell sources and the best delivery strategies for growth factors. The situation will be complicated in the case of osteochondral constructs, in which each layer has different specifications and their contact must avoid any delamination or subsidence of the scaffold in vivo.

In this review, some osteochondral TE strategies that have been proposed are overviewed. Some topics in this context are focused particularly, including the new trends for scaffold design, the choice of the right osteogenic/chondrogenic cell sources and materials and the need for developing new culture methods.

\section{Materials}

In osteochondral approaches, many of the concepts that have been proposed are based on the use of two distinct materials, each one being adequate to integrate with each tissue (see Figure 1 for the most widely accepted strategy). Many types of materials have been proposed for both cartilage and bone TE, most of them biocompatible and biodegradable polymers that followed previous applications in surgical procedures or other biomedical applications. An exhaustive description is not given here; much information may be found in other review papers (Chen et al., 2002; Frenkel and Di Cesare, 2004; Gomes and Reis, 2004; Salgado et al., 2004; Woodfield et al., 2002). However, we can systematize the origin of relevant materials in three major groups:

1. Natural-based polymers. Adequate materials for TE applications should ideally mimic the naturally occurring environment of the tissue, and natural polymers usually contain domains that can send important signals to guide cells at various stages of their development (Galois et al., 2004; Langer, 1999; Mano et al.,. in press; Thomson et al., 1995a). However, such bioactivity can cause problems with antigenicity (Thomson et al., 1995a) and the processability is often difficult. The most used sources of natural derived polymers 


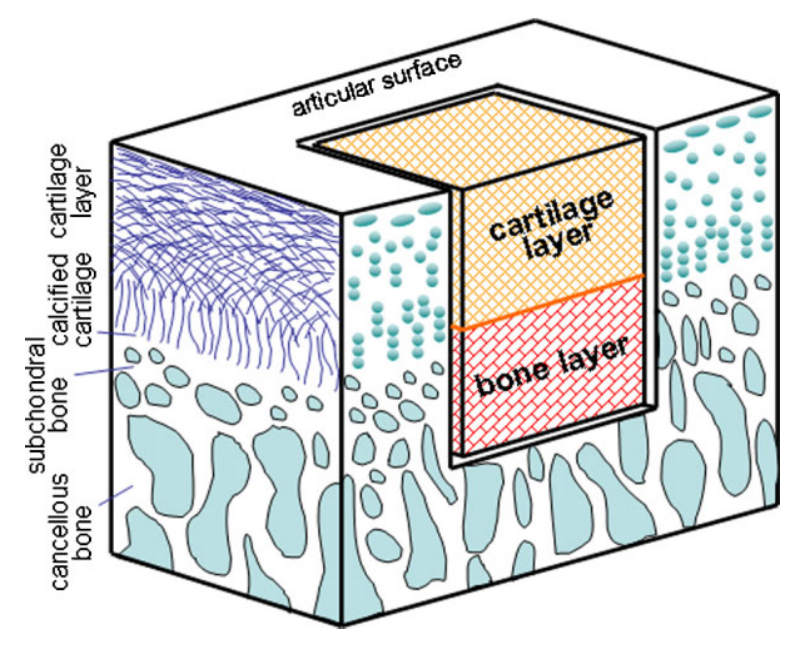

Figure 1. Schematic representation of a osteochondral defect showing the collagen fibres (left face) and the chondrocytes (right face) of the cartilage layer (upper side), the bone region (bottom), and the osteochondral implant

include proteins, especially from extracellular matrices (e.g. collagen or glycosaminoglycan), polypeptides, polysaccharides (including chitosan, starch, hyaluronic acid and alginate) and poly(hydroxyalkanoates).

2. Synthetic polymers. Such systems offer a wide range of chemical and processability variety, and in some cases may be obtained with controlled distribution of molecular weights. The most popular biodegradable synthetic polymers include poly ( $\alpha$-hydroxy acids), especially poly(lactic acid) (PLA), poly (glycolic acid) (PGA) and their co-polymers (PLGA), poly( $\varepsilon$-caprolactone), poly(propylene fumarate), poly(dioxanone), polyorthoesters, polycarbonates, polyanhydrides and polyphosphazenes. Natural and synthetic polymers have their own specificities, and we believe that the right combination of both can bring together the advantages of the two kinds of materials, offering more possibilities to produce superior solutions. Another strategy that one should have in mind is to look for materials selection beyond the currently available materials that were developed originally for other applications. The design should have a bottom-up approach and the materials should be able to recognize or be recognized by the tissue environment, and react accordingly, and also mimic the extracellular matrix to help guide morphogenesis and tissue repair. An elegant example is the development of hydrogels that have cell-mediated proteolytic invasiveness capability (Lutolf et al., 2003). Another fundamental issue, which will be not developed here, is surface modification of devices that allows to the biological response to be tailored while maintaining the bulk properties of the materials.

3. Ceramics, glasses and composites. Many studies have been devoted to the understanding of the fundamentals of biomineralization and the use of such knowledge in developing biomaterials with improved properties for bone TE (Reis et al., 2004). Ceramics, such as hydroxyapatite (HA) or other calcium phosphate (Ca-P) ceramics (including tricalcium phosphate, TCP) or bioactive glasses (such as Bioglass ${ }^{\circledR}$ ) are known to promote, when implanted, the formation of a bone-like apatite layer on their surfaces. This is considered to be a positive characteristic in terms of bone-bonding behaviour, assuring enhanced fixation of the implant (Huang et al., 1997; Li et al., 1992, 1997; Oonishi, 1991; Peitl et al., 1996). The inorganic phase can be combined with polymers or polymer precursors that will allow produce bioactive, inert, biodegradable or injectable composites to be produced (Mano et al., 2004). Much effort has been expended in finding new strategies for creating Ca-P coatings similar to bone apatite, through biomimetics or other processing routes, even in biomaterials that are not a priori bioactive (Oliveira et al., 2003; Reis and Weiner, 2004). Inclusion of growth factors in the scaffolds may be a route for its controlled delivery during the differentiation process. An interesting concept is the inclusion of cytokines or morphogenetic factors, such as BMP-2, into biomimetic Ca-P coatings (Liu et al., 2005). Note, in the context of osteochondral TE, that the region of the implant that will be in contact with the bone should have bioactive behaviour, but one should avoid any calcification on the cartilage side.

\section{Scaffold design and processing}

Scaffolds will provide a shape, guide tissue development and permit the convenient delivery of cells into patients. Whatever the tissues under consideration, the scaffolds should ideally be biodegradable and the degradation rate should match the extracellular matrix produced. Generically, three-dimensional (3D) porous scaffolds or hydrogels are the most widespread solutions for TE constructs, due to the high standard of cellular attachment and mechanical stability that is attained. Besides the materials and subsequent surface modification, the macrostructure of the scaffolds plays an important role, not only in the resulting mechanical properties but also on the proliferation and migration of seeded cells into the matrix. For the particular case of bone formation in vitro and in vivo, the role of porosity and pore size was reviewed by Karageorgiou and Kaplan (2005).

Many techniques have been used to produce scaffolds, and in most cases they can be used for both bone and cartilage TE; they include: solvent casting and particulate leaching (Agrawal et al., 1997; Holy et al., 2000; Lin et al., 2002; Mikos et al., 1994; Murphy et al., 2002; Yoon and Park, 2001), phase inversion/inversion (Holy et al., 2000; Karp et al., 2003; Mooney et al., 1996), fibre bonding (Gomes et al., 2003; Guidoin et al., 2000; Hutmacher, 2000; Kim and Mooney, 1998; Li et al., 2001; Mikos et al., 1993a; Vunjak-Novakovic et al., 1998), melt-based technologies (Gomes et al., 2001, 2002; Thomson et al., 1995b; Washburn et al., 2002), membrane lamination (Mikos et al., 1993b), high pressure-based methods 
(Mooney et al., 1996; Shea et al., 2000), supercritical fluid technologies (Quirk et al., 2004), freeze drying (Madihally and Matthew, 1999; Mao et al., 2003; Schoof et al., 2001) and rapid prototyping techniques/free-form fabrication (Hutmacher, 2000; Hutmacher et al., 2004; Leong et al., 2003; Park et al., 1998; Woodfield et al., 2004; Zhang et al., 2005).

As discussed further below, many TE concepts dealing with osteochondral repair involve the design of bilayered scaffolds that could regenerate both cartilage and subchondral bone. Most of the processing techniques already mentioned may be used, but different combinations of materials and morphologies in both sides of the scaffold will complicate the production of such structures. This aspect will be analysed in more detail in Section 5; here, just a few generic and representative examples will be given. Moreover, osteochondral constructs are typically fabricated in the shape of a cylinder, which is more appropriate to address the clinical needs of replacing localized arthritic defects.

Kawanishi et al. (2004) combined two different processing techniques to obtain PLGA scaffolds with two layers exhibiting different morphologies. A 1,4-dioxane solution of PLGA was added to a mould containing trisodium citrate particles in the bottom; as the level of the solution was higher than the thickness of the particle layer, freeze-drying followed by the leaching of the particles allowed a bilayered structure with two distinct porous organizations to be obtained. In another study, it was shown that it is possible to develop 3D porous bilayer hydroxyapatite-chitosan scaffolds by combining a sintering and a freeze-drying technique (Ghosh et al., 2006; Oliveira et al., 2006): The HA scaffolds, aimed to be integrated into the bone side, were obtained by sintering a polyurethane sponge filled with an HA slurry; a viscous chitosan solution was added into the top of the ceramic scaffold and the corresponding porous structure, adequate for the cartilage side, was produced by freeze-drying. This method allowed the two layers to be well integrated, as the chitosan partially penetrated into the top region of the ceramic scaffold. Good integration was obtained by combining two layers with a common thermoplastic; the bottom layer, comprising PLA reinforced with HA, and the top layer, comprising a blend of starch and PLA, were processed by compression moulding after compounding with salt particles (Ghosh et al., 2006). A partial overlap between the two layers was obtained and the two layers exhibited physicochemical features adequate for both tissues. Taguchi et al. (2004) developed a scaffold with gradient calcium phosphate, using an alternative soaking methodology in type II collagen gels that had one side masked with a silicone sheet. This procedure enabled gels to be obtained in which one of the half sides was much richer in calcium phosphate, thus apparently being more appropriate for integration into the subchondral bone. Such examples clearly demonstrate the variety of possibilities that exist in producing scaffolds aimed for use in TE for the regeneration of osteochondral defects.
The use of injectable scaffolding materials is a more recent and promising approach to be employed in osteochondral TE. For example, Kang et al. (2006) mixed rabbit chondrocytes with PLGA microspheres and injected this mixture into full-thickness wounds made in the knees of rabbits; 16 weeks after transplantation it was observed that the chondrocytes were able to form white cartilaginous tissue, indicating the potential of this procedure in osteochondral wound repair. Another approach in this context was the development of a thermoreversible hydrogel of $\mathrm{P}$ (NIPAAm-co-AAc) and hyaluronic acid, which were used as injectable carriers of rabbit chondrocytes and a growth factor ( $\mathrm{Na}$ et al., 2007); the results again showed that this system could also be promising for the induction of neocartilage formation, especially in the presence of the growth factor.

\section{Cells}

The choice of an adequate cell source is critical in any TE strategy based on autologous cells. TE of osteochondral parts is constrained by the need for the growth and function of two different tissues - cartilage and bone-despite deriving from common progenitor cells. In osteochondral TE approaches some authors opted to use, for example, just chondrocytes in the region of the scaffold that will be integrated with cartilage (see examples in next section). However, scaffolds seeded with both osteoprogenitor and chondroprogenitor cells may be needed to achieve enhanced integration with the host tissues and mechanical function, especially in large defects.

The most direct cell source is obtained from the isolation of mature cells (osteoblasts and chondrocytes) throughout biopsies taken from the patients, followed by an expansion in vitro. However, the number of cells that can be harvested is low and the expansion rates of the cells are also relatively small, which will limit the amount of cells available to be seeded onto the scaffolds. The expansion of primary cells may also result in a degradation of their functionality, e.g. the expansion of articular chondrocytes can lead to the expression of fibrocartilage (Lipman et al., 1983). Such drawbacks may be surpassed using undifferentiated stem cells. The use of such undifferentiated cells could be a suitable way to use a single autologous cell source in osteochondral approaches, which may provide both kinds of cells needed while eliminating the risk of immunological rejection and transmission of infectious diseases. A discussion that should be raised in this context is the use of growth factors, polypeptides that can either stimulate or inhibit cellular proliferation, differentiation, migration, adhesion and gene expression, by upregulating or downregulating the synthesis of proteins, cytokines and receptors (Jadlowiec et al., 2003; Rose and Oreffo, 2002). Such molecules could be directly loaded during or after scaffold fabrication, and several strategies have 
been proposed for growth factor delivery (Babensee et al., 2000; Rose et al., 2004). As reviewed by Woodfield et al. (2002), it has been proposed that cartilage growth and maturation is supported by growth factors, including insulin-like growth factor-1 (IGF-1), transforming growth factor beta-1 (TGF- $\beta 1$ ), fibroblast growth factor-2 (FGF-2) and bone morphogenetic proteins (BMP-2 and BMP-3). The delivery of more than one growth factor may be beneficial; in a particular study, Holland et al. (2007) investigated the delivery of single and dual growth factors (TGF- $\beta 1$ or IGF-1) in cartilage repair. Like cartilage, bone also possesses a large variety of growth factors, including TGF- $\beta$, BMP-2, $-4,-6$ and -7, IGF-1 and -2 and platelet-derived growth factor (PDGF; see further discussion in Salgado et al., 2004), being also involved in the regenerative process. For osteochondral approaches, one clearly needs the controlled delivery of various growth factors, with different delivery rates at different sites of the scaffold, so that the right signals may be transmitted for both kinds of tissue.

Stem cells may have different origins and have the possibility, under certain conditions and with different potential, to give rise to specialized cells of body tissues and organs. Pluripotent embryonic stem cells (ES cells), first isolated from the inner cell mass of the blastocyst (Evans and Kaufman, 1981; Martin, 1981), are characterized by two unique properties, a nearly unlimited self-renewal capability and a capacity to differentiate via precursor cells. Although there is enormous potential for biomedical and TE applications of such cells, there are still several issues to be addressed, including the tumorigenic potential of ES cell-derived somatic donor cells, or their immunological incompatibility, and ethical and social questions associated with the use of ES cells in regenerative medicine.

Well accepted by society, mesenchymal stem cells are also capable of differentiation along multiple mesenchymal lineages (Jorgensen et al., 2004) and are present in many adult mesenchymal tissues, including bone marrow (Tuan et al., 2003). Discussions on the biological aspects of such cells, including their expansion and differentiation potential, were reviewed by Gregory et al. (2005). Bone marrow stromal cells (BMSCs) can be regarded as a mesenchymal progenitor cell population derived from adult stem cells. BMSCs can be obtained in large numbers in culture if the right conditions are provided, e.g. it was found that the proliferation and maintenance of differentiation potential in these cells may be achieved through FGF-2 supplementation to the culture medium (Martin et al., 1997). Some authors consider BMSCs to be the most interesting cell system for use in connective TE (Cancedda et al., 2003).

Adipose tissue is also an abundant and accessible source of adult stem cells, which can be isolated from liposuction waste tissue by collagenase digestion and differential centrifugation (Gimble and Guilak, 2003a, 2003b). It has been shown that human adipose-derived stem cells are multipotent, capable of differentiating along adipocyte, chondrocyte, neuron, osteoblasts and skeletal myocyte pathways (Erickson et al., 2002; Gimble and Guilak, 2003a, 2003b; Halvorsen et al., 2001; Zuk et al., 2001, 2002). Therefore, they could also be a very interesting source of progenitor cells with potential for use in osteochondral therapy.

\section{Tissue engineering strategies}

\subsection{Single-layered scaffolds}

Some authors suggest that osteochondral implants could be constructed from single-layer scaffolds. The typical concept here consists of seeding autologous chondrocytes in the top of the three-dimensional scaffold to create a cell-scaffold construct for in vivo implantation. For example, experiments were made using sheep models, where $\beta$-TCP bioceramic scaffolds were used to support autologous chondrocytes extracted from the humeral head (Guo et al., 2004); although no long-term in vivo studies were reported, these strategies were able to lead to the formation of neocartilage tissue on the surface, where hyaline cartilage structure was typically generated after 24 weeks. In another study, hyaluronan-based scaffolds coated with fibronectin were also seeded, or not, with autologous bone marrow prior to implantation in osteochondral defects of New Zealand white rabbits (Solchaga et al., 2002). The hypothesis was that bone marrow contains osteochondral progenitor cells and bioactive agents that could induce the reconstruction of both cartilage and bone in such defects, when supported by the scaffold. Four weeks after implantation, the defects were filled with bone, well integrated to a top layer of cartilage. However, this study showed that the inclusion of bone marrow in the scaffolds did not reveal statistically superior performance with respect with the control without cells, as judged from histological scores of the specimens. Another study in this context was performed in order to compare hyaluronanbased scaffolds, with two different degradation rates, and two polyester-based scaffolds, also with two distinct degradation rates (Solchaga et al., 2005). This work showed that the degradation profile is a critical parameter for the repair process. Thicker cartilage is formed in slowly dissolving scaffolds, although presenting more cracks and discontinuities, and bone formation is also delayed at the base of the defects.

Other strategies can be used to maintain the chondrocytes in the top of the scaffold. van Susante et al. (1998) suspended isolated chondrocytes in fibrin glue. This cell-glue suspension was loaded onto a HA cylindrical scaffold that would integrate the subchondral bone. Although some hyaline-like cartilage could be detected at the HA-glue interface, a layer of fibrous tissue was formed surrounding the HA graft, destabilizing the fixation of the implant. Moreover, this strategy led to a resurfacing of the joint with essentially fibrocartilaginous repaired tissue. Another procedure was used by Wang et al. (2004) to produce neocartilage on the 
top on scaffolds from different origins - poly(L-lactide), poly(D,L-lactide) and collagen-HA. Porcine chondrocytes were seeded on the top of the scaffolds in adapted cylindrical dialysis chambers. After 15 weeks, a viable neocartilage layer was formed on each material, where, comparatively, collagen-HA constructs were found to be superior to the other formulations in terms of cell viability, construct shape and cellular integration. Also, the top of demineralized bone matrix gelatin scaffolds were seeded with rabbit chondrocytes and cultivated for 6 weeks (Li et al., 2006); different characterization techniques were used to demonstrate that viable hyaline-like neocartilage tissue could also be produced on the construct.

In another study, Tuli et al. (2004) press-coated a chondrifying high-density pellet of trabecular bonederived human mesenchymal progenitor cells onto a PLDLA scaffold. This construct was maintained in a chondrogenic medium and subsequently loaded in the other extremity with cells from the same source but previously initiated to undergo osteogenesis. The ensemble was then cultured in a cocktail medium that was able to maintain both chondrogenesis and osteogenesis. This is one of the few studies, with very encouraging in vitro results, where a single source of human progenitor cells was used to produce a osteochondral hybrid construct. Clearly, more studies are needed in that direction, combining different materials and scaffold architectures, and optimized media should be developed to allow for co-cultures.

Single-material scaffolds may be processed with a specific design that could be adequate for osteochondral applications, e.g. using rapid prototyping techniques. Fused deposition modelling is adequate to fabricate reproducible and computer-controlled porous architectures, where the two sides of the osteochondral construct may have distinct structures and shapes (Cao et al., 2003; Hutmacher, 2000). This aspect was analysed using polycaprolactone-based honeycomb-like scaffolds, where both osteogenic and chondrogenic cells were seeded separately in the two regions of the scaffolds and cultivated in a co-culture medium (Cao et al., 2003); it was found that the cells proliferate in their compartments for more than 50 days and produce extracellular matrix.

In order to investigate the influence of the age of donor cells and the age of the host on osteochondral repair, cells derived from perichondrium were cultured in a PLA scaffold and transplanted into osteochondral defects of adult or aged female rabbits (Morihara et al., 2002). For such fundamental studies where just one question is addressed, simple protocols such as this one seem to be preferable. Another example in this context is the study the effect of transforming growth factor- $\beta 1$ (TGF- $\beta 1$ ) on the development of osteochondral tissue (Angele et al., 1999): it was found that preculture in a chondrogenic medium increased the formation of new tissue in hyaluronan-gelatin composite constructs.

\subsection{Bilayered scaffolds}

Although single-material scaffolds may be easier to prepare, the simultaneous regeneration of two tissues should involve adequate support for both kinds of cells, which will interact differently with the same material. Furthermore, articular cartilage is a complex tissue, whose performance will be influenced by the mechanical support of the subchondral bone (Radin and Rose, 1986). Therefore, an alternative strategy should include the construction of bilayered structures, especially adequate to incorporate, in a favourable environment, two types of cells requiring different chemical surroundings, mechanical features and pore morphology. This would allow guiding the growth of two different tissues, satisfying the different biological requirements. Therefore, heterogeneous structures should be built, in which one of the sides promotes cartilage regeneration and the other region, exhibiting different properties, is designed to encourage bone integration. For example, the cartilageside layer should be more ductile and should have much more fluid uptake capability. The bone-side layer should exhibit higher stiffness, should preferably have a good affinity to the ceramic constituent of bone and, ideally, should be able to induce vascularization, especially for large defects. Ideally, adequate surface modification of the pores in the two sides of the scaffold should be performed independently, as chondrocytes and osteoblasts may react differently to a given surface treatment of the biomaterial.

Three possible concepts are shown in Figure 2 for the preparation of TE constructs based on bilayered scaffolds, and some examples are given below.

\subsubsection{Scaffolds from two independent layers}

The easiest way to construct a biphasic scaffold is to build the two layers independently and join them prior the implantation (Figure 2A). Whether or not bioreactors are used, this allows the cultivation of both chondrogenic and osteogenic cells in separate media and environmental conditions. The main disadvantage is that the integration between the two layers may not be easily achieved.

For the bone layer, Niederauer et al. (2000) used poly(D,L-lactic acid-co-glycolic acid) reinforced, or not, with PGA fibres, Bioglass ${ }^{\circledR}$ or calcium sulphate; for the cartilage side, the same matrix was used, reinforced, or not, with PGA fibres. The two phases were glued together using a small amount of solvent. Half of the implants were seeded with autologous goat primary chondrocytes and implanted for 16 weeks after culture. In most cases a high percentage of hyaline cartilage and good bone restoration were found, in which case the addition of cells was found not to significantly improve healing.

Kreklau et al. (1999) engineered a biphasic joint cartilage, using a non-woven mesh consisting mainly of PGA : PLA (9:1), previously seeded with bovine-derived chondrocytes supported by a block of calcite or calcium carbonate from coralline material. The cell-polymer structure was affixed to the ceramic support with a 

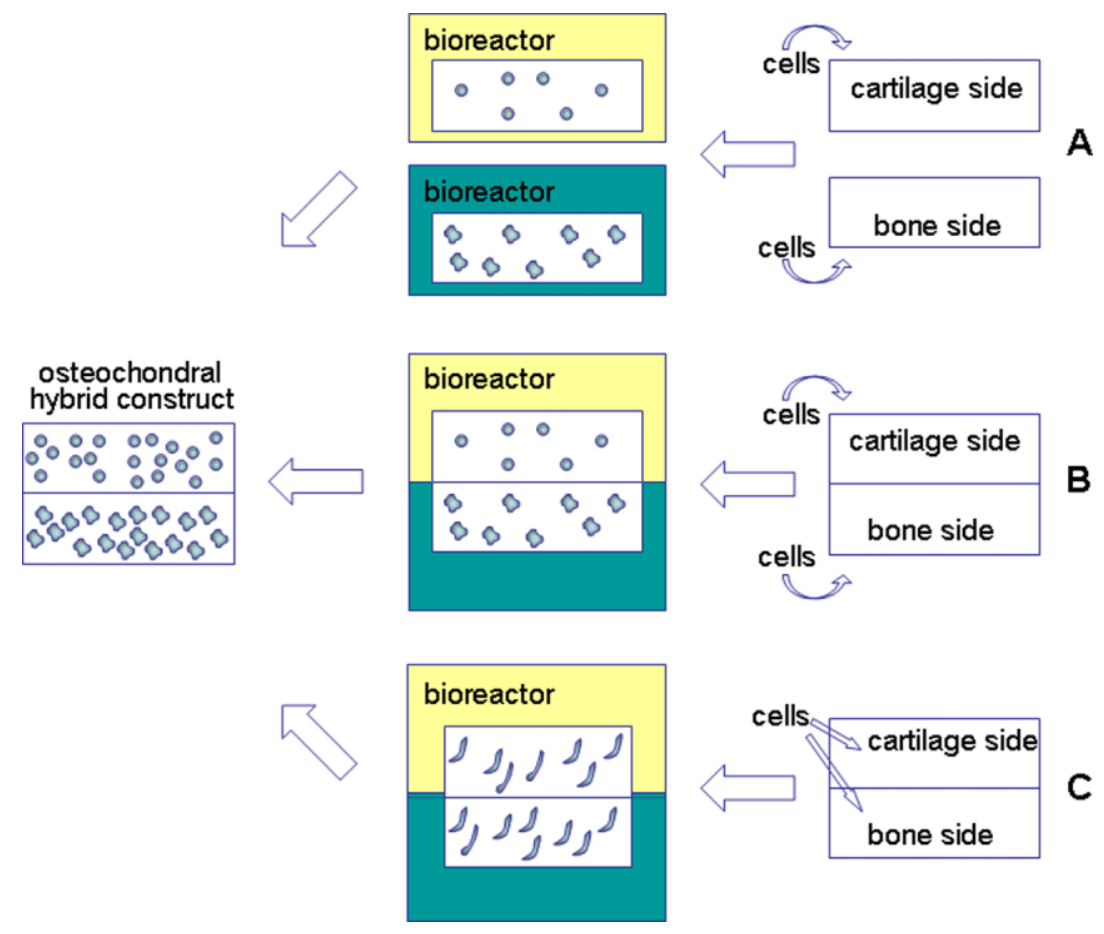

Figure 2. Three possible strategies for constructing hybrid constructs for osteochondral TE: A - the cell culturing is performed independently in two sides, that are integrated before implantation; B - two different cell sources are seeded in the two sides of a bi-phasic scaffold, and cultivated in a special bioreactor with two separated chamber; $\mathrm{C}-$ common progenitor cells are seeded in the two sides of a bi-phasic scaffold that contains different differentation agents and then cultivated in a bioreactor with two chambers

fibrin-cell solution, and the hybrid constructs were incubated in perfusion culture chambers. The polymer hybrid construct formed a new matrix and fused with the underlying biomaterial, but further in vivo tests would be required to fully validate this concept; moreover, it was not clear whether the use of bulk calcite supports would be adequate in osteochondral repair. Another example of integration of two layers using fibrin sealant was the combination of a hyaluronan-based sponge for the cartilage side, and a calcium phosphate scaffold for the bone side (Gao et al., 2001). The two layers were previously seeded with rat bone marrowderived mesenchymal stem cells and culture-expanded separately in two different media that could stimulate the differentiation of chondrocytes or osteoblasts. This strategy allowed the formation of fibrocartilage in the polymeric component, whereas bone was formed in the ceramic layer. Fibrin glue was also used to join two chitosan-based layers produced independently from a particles aggregation methodology (Malafaya et al., 2005): the bone-layer was produced from chitosan-HA composite particles, whereas the cartilage layer was produced using chitosan-only particles.

Schaefer et al. (2000) also used PGA-based materials to produce osteochondral constructs: for the cartilage layer, chondrocytes were seeded on non-woven PGA meshes, whereas periosteal cells were dynamically cultured into PLGA-polyethylene glycol foams in chondrogenic medium supplemented with osteogenic medium. Both cartilaginous and bone-like constructs were independently cultured for 1 or 4 weeks, sutured together at two edges and cultured in osteogenic medium for an additional 4 weeks. It was found that the bilayered constructs were structurally stable. Moreover, the fraction of glycosaminoglycan increased with time in the cartilaginous region, whereas mineralization was produced in the bone layer during the isolated culture. In another study, human chondrocytes and osteoblasts were seeded separately in fibrous PGA disks that were sutured together and cultured in a bioreactor (Mahmoudifar and Doran, 2005a). Suturing was also used to join the chondral and osteo layers, each one produced by lamination of PLGA-collagen hybrid meshes (Chen et al., 2006b); before suture and subcutaneous implantation in nude mice, canine chondrocytes and canine bone marrow stromal cells were cultivated in the two layers. Although not implanted in osteochondral defects, the construct was found by the authors to have potential to be used in TE, as osteochondral-like tissue was found to be formed (Chen et al., 2006b).

Both layers of an osteochondral construct may be placed in the defect site through a press-fitting effect. Schaefer et al. (2002) utilized two kinds of scaffold, a non-woven mesh formed from PGA fibres with a void volume of $97 \%$ for the cartilage side, and a sponge made of bovine type I fibrillar collagen, HA and TCP (Collagraft) as the subchondral support. Chondrocytes were harvested from the articular cartilage of male New Zealand white rabbits and dynamically seeded onto PGA scaffolds in order to engineer cartilage. The subchondral support allowed the fixation of the engineered cartilage by press-fit. Four groups were tested: (a) the defect was 
left empty; (b) similar defects were treated with cellfree osteochondral scaffold; (c) cartilage was engineered over the Collagraft support; (d) defects were treated with engineered cartilage and the Collagraft support, onto which fresh bone marrow was adsorbed. That study showed that such composites, when press-fitted into large osteochondral defects in the animal model utilized, withstood physiological loading and remodelled over 6 months into osteochondral tissue with adequate features. The integration with bone was positive, but the composites did not integrate well with host cartilage. The existence of bone marrow in the subchondral support did not influence the tissue remodelling, i.e. group (d) vs. group (c). Structurally, 6 month repairs in groups (c) and (d) were superior to those in group (b), indicating the importance of the previous culture of chondrocytes in the top layer. Defects repaired with engineered cartilagebased composites exhibited physiological mechanical performance, compared with group (a), showing the importance of the scaffold for the recovery of the mechanical integrity of the defect.

Another approach for integrating the two layers is by joining them through a biodegradable external fixation. Schek et al. (2004) used layers of PLA and HA, processed by solid free-form fabrication and seeded with fully differentiated chondrocytes and fibroblasts transduced with an adenovirus expressing bone morphogenetic protein 7 , respectively. The two phases were assembled before cell seeding and subcutaneous implantation into mice, using a thin PGA film between the layers, and PLA rods that traversed the polymer and ceramic phases were used to attach the two layers. This approach allowed the simultaneous growth of bone, cartilage and mineralized interface tissue.

In another strategy (Gao et al., 2002), the bone side of an osteochondral defect of New Zealand white rabbits was filled with a self-hardening injectable calcium phosphate. As this is initially a paste, the material will fill the irregular contours of the base of the defect, and it hardens at temperatures of $20-37^{\circ} \mathrm{C}$, with biomechanical properties similar to lamellar bone. Then a hyaluronan sponge, previously loaded or not with autologous bone marrowderived progenitor cells, was inserted on the cartilage side. After 12 weeks, repaired tissue composed by chondrocytes arranged in a columnar array was observed on the cartilage side. A higher cellular density was observed in the healing tissue of the hyaluronan scaffolds loaded with cells than in the control without cells. The ceramic side also evidenced high osteoblastic/osteoclastic activity and rapid new bone formation. Note that, in that case, there was not a direct joining of the two layers but the ensemble seemed to integrate well to the osteochondral defect.

\subsubsection{Integrated bilayered scaffolds}

Different strategies may be envisaged to produce well integrated bilayered porous osteochondral constructs prior to cell culture. For example, two different sources of cells can be seeded in the two layers before bioreactor expansion (Figure 2B); alternatively, cells from a single progenitor source are seeded in the scaffold, and the differentiation and expansion will be accomplished during culture (Figure 2C).

In a first concept, a gel (or gelling solution) suitable for the selective growth of cartilage is impregnated into one of the sides of a previously prepared bony substrate. For example, it was suggested that agarose could be an adequate vehicle to carry chondrocytes at the top of devitalized trabecular bone disks from bovine tibia (Hung et al., 2003). The suspension of bovinederived chondrocytes in agarose was added over the ceramic scaffold and the hybrid construct was cultured for 42 days after gelling. The chondrocytes remained viable during this time, and the agarose maintained its shape while remaining attached to the underlying bony substrate. In this case, the agarose-cell suspension could penetrate deeply into the construct. In another study, Lima et al. (2004) reported simulation studies in which large non-homogeneous mechanical signals were found within such osteochondral constructs, that could aid in the development of heterogeneity in the mechanical environment felt by the cells seeded in the engineered scaffolds. Similarly, dry ceramic cubes derived from cancellous bone from calf femoral condyles were soaked into a gelatin solution is such a way that one of the extremities of the scaffold could be impregnated by the solution through diffusion (Chang et al., 2004). The gelatin was crosslinked with glutaraldeyede and a biphasic construct was produced, as a portion of gelatin was left outside the calcined bone scaffold. Porcine articular chondrocytes were seeded in the gelatin layer and the osteochondral scaffolds were cultured in a doublechamber bioreactor; after 4 weeks, hyaline cartilage could be observed in this region. A similar strategy, presented previously, used a viscous chitosan solution that partially impregnated a ceramic scaffold to produce a bilayered structure (Oliveira et al., 2006). By changing the viscosity of the chitosan solution, the degree of penetration into the bone layer could be controlled, as well as the porous structure of the chitosan foam. Fibrin glue was also tested as the cartilage part in hybrid scaffolds in which poly(caprolactone) scaffolds acted as the bone compartment (Shao et al., 2006); however, although the synthetic polymer showed potential as a matrix for osteochondral bone regeneration, the fibrin glue was found not to be a functional scaffold for the reconstruction of articular cartilage at a weight-bearing site.

Another strategy is based in the use of common materials in the upper and lower layers. For example, collagen was used in both a dense collagen layer aimed to be in contact with bone and a porous collagen matrix for the cartilage side, where chondrocytes were seeded (Frenkel et al., 1997); histological data allowed the conclusion that the implants containing cells presented better results that the control implants without cells. In another study, oligo[poly(ethylene glycol) fumarate], with or without gelatin microparticles (intended to speed 
scaffold degradation through enzymatic digestion and to deliver TGF- $\beta 1$ ), was used to produce bilayered structures (Holland et al., 2005). A two-step crosslinking procedure enabled the composition of the two layers to be controlled independently. This study was intended to evaluate how the presence of growth factors in the layers affects the regeneration of osteochondral defects in rabbits. No significant variations were found in the development of subchondral bone, but the inclusion of TGF- $\beta 1$ in the top layer appeared to exert some therapeutic effect on hyaline cartilage formation. As noted previously, good integration was also achieved using PLLA as a common material in the two layers, in the top layer blended with starch and in the bottom layer reinforced with HA, with the layers connected through compression moulding (Ghosh et al., 2006). Also, a polyester-based biphasic scaffold was produced, in this case processed by a $3 \mathrm{D}$ printing process (Sherwood et al., 2002): the upper cartilage region was composed of D,L-PLGA-L-PLA, with $90 \%$ porosity, and the bone portion consisted of a $55 \%$ porous L-PLGA-TCP composite. The good transition between the two layers prevented delamination. The osteochondral devices were cultured rotationally by submerging in a tube, or topseeded by pipetting ovine articular chondrocytes onto the top of the scaffold. Cartilage was formed in the top region of the construct during a 6 week in vitro culture period and the tensile strength of the bone region was found to be of the same order as fresh cancellous human bone. Finally, in another study, collagen was used in both cartilage (collagen sponge) and bone (PLGA-collagen composite scaffold) layers, where the collagen fraction in the two regions was connected (Chen et al., 2006a). The biphasic scaffolds were used to culture canine-derived BMSCs that were then implanted into a canine osteochondral defect; after 4 months of implantation, cartilage- and bone-like tissues were formed in the corresponding layers, indicating that the developed scaffold could have potential for use in osteochondral TE (Chen et al., 2006a).

The above-mentioned examples clearly demonstrate that, despite the enormous variety of materials, scaffold designs and cells that have been tested for osteochondral TE, it is not yet clear which would be the most advantageous strategies to adopted or pursue. In fact, the reported studies have used specific scaffolds and test conditions that could hardly be compared with one another. Therefore, despite the great efforts that have been made, more integrated work is needed to seek improved methodologies that could be transposed to clinical practice.

\subsection{Bioreactors}

It has been known for a long time that cells and tissues react to external mechanical stimuli that can include gravitational and hydrostatic pressures, shear stresses caused by fluid flow, acoustic waves and contractile forces exerted from one cell to another. Janmey and Weitz (2004) very elegantly reviewed several aspects of the effect of forces in the behaviour and response of cells and provided a valuable bibliography. Bone mechanotransduction and its relevance in the biomaterials area was also well reviewed by Sikavitsas et al. (2001). A huge number of studies have demonstrated that the biological environment of tissues such as bone and cartilage is highly influenced by mechanical forces felt by the cells. Therefore, similar physiological conditions should be ideally reproduced in vitro during cell culture within the scaffolds. Such conditions can be obtained in adequate bioreactors that also have other advantages, including enhancement of the transport of nutrients towards the inner regions of the scaffold and release of waste products, thus providing a correct mass transport rate. Different bioreactor designs have been proposed to dynamically culture cells in hybrid constructs, including spinner flasks, rotating-wall bioreactors (that simulate the effect of microgravity) and perfusion-based bioreactors (for a literature survey, see e.g. Martin et al., 2004; Salgado et al., 2004; Sikavitsas et al., 2001; for a review focusing on the use of bioreactors in engineering osteochondral grafts, see Wendt et al., 2005). There are also bioreactors that are basically designed to just apply forces to the scaffolds, e.g. through compression loading (Demarteau et al., 2003a, 2003b; Hung et al., 2004; Kisiday et al., 2004; Lee et al., 2003; Waldman et al., 2004), giving valuable fundamental insights on the effect of mechanical stress in tissue formation.

Most bioreactors have been created to operate in single scaffolds, and they could be used in osteochondral constructs provided that the correct co-culture conditions are used. As an example, it was suggested that a simple recirculation bioreactor (Mahmoudifar and Doran, 2005b) could be used in double-layered PGA disks seeded with chondrocytes and osteoblasts in each side, where glycosaminoglycan could be detected just in the cartilage layer and only the bone layer was mineralized (Mahmoudifar and Doran 2005a).

Increased versatility may be achieved in osteochondral TE if the two layers of the scaffold are cultivated separately. This will be facilitated if the two layers are initially separated (see possibility A in Figure 2). If the two layers are already integrated and are to be cultivated simultaneously (Figure 2B, C), then new strategies must be adopted where typically a double chamber should be used to differentiate the culture conditions. A possibility for such a bioreactor is to separate these two chambers by a hollowed wall where the central part of the bilayered scaffold is fixed (Hutmacher, 2000); in this design, the two sides of the scaffold will be in independent contact with the corresponding medium and each chamber will have its own tissue culture and gas inlets and outlets. A system using such a strategy was tested in a gelatin/calcium phosphate biphasic scaffold described previously (Chang et al., 2004). This bioreactor consisted of two tubular glass chambers, each having four branch tubes, for medium inflow and outflow, for oxygen ventilation, and an extra one for other functions 
whenever necessary. The chambers were separated by a silicone rubber septum with several holes to hold the biphasic scaffolds. The apparatus also allowed mixing of the media and mechanical stimulation through magneticbar stirring, and the entire system could be put into an incubator. This bioreactor could then used to culture both osteoblasts and chondrocytes, but in that study only the latter were seeded in the gelatin side of the scaffold.

\section{Future challenges}

A major goal in osteochondral $\mathrm{TE}$ is to be able to promote tissue synthesis derived from progenitor cells, preferentially from a single cell source, that will be differentiated in the construct to chondrocytes and osteoblasts. This will require the incorporation of cell adhesion molecules and specific growth factors in different regions of the construct for TE chondrogenesis and osteogenesis. In this context, smarter systems should be developed where such active molecules could be released with specific profiles and at specific locations. A corollary for that is the need for improved bioreactors able to culture both regions simultaneously in separate reservoirs and different conditions. Alternatively, single chamber bioreactors could be used, provided that optimized media are effective to promote cell proliferation in both compartments. New specifications are also required in the bone region in order to allow for rapid and correct vascularization. Co-culture of endothelial cells may be a strategy to promote neo-angiogenesis, but the correct conditions to achieve a functional hybrid construct remain to be elucidated.

The materials, degradation profiles and architectures of porous structure must be different in the different regions, as different cells will require different $3 \mathrm{D}$ environments to adhere, proliferate and guide extracellular matrix formation. Many possibilities exist for producing optimized scaffolds, and combinatorial approaches may be needed to progress. The number of possibilities also increases further if one opts to modify the surface of the pores, either through physical or chemical routes, or to incorporate active agents. This would provide an adequate and specific chemical environment that could induce and specify differentiation of progenitor cells, enhance cell adhesion and proliferation or induce mineralization in the bone side.

\section{Acknowledgements}

Financial support for this work was provided by FCT, through the POCTI and FEDER programmes, and by the European Union-funded STREP Project, HIPPOCRATES (NMP3-CT-2003505758).

\section{References}

Agrawal CM, Athanasiou KA, Heckman JD. 1997; Biodegradable PLA-PGA polymers for tissue engineering in orthopaedics. Mat Sci Forum 250: 115-128.

Aigner T, McKenna L. 2002; Molecular pathology and pathobiology of osteoarthritic cartilage. Cell Mol Life Sci 59: 5-18.

Angel MJ, Razzano P, Grande DA. 2003; Defining the challenge - the basic science of articular cartilage repair and response to injury. Sports Med Arthrosc Rev 11: 168-181.

Angele P, Kujat R, Nerlich M, et al. 1999; Engineering of osteochondral tissue with bone marrow mesenchymal progenitor: cells in a derivatized hyaluronan-gelatin composite sponge. Tissue Eng 5: 545-553.

Atala A. 2007; Engineering tissues, organs and cells. J Tissue Eng Regen Med 1: 83-96.

Attmanspacher W, Dittrich V, Stedtfeld HW. 2000; Our experience with the arthroscopic therapy of chondral and osteochondral defects of the knee with the OATS (c). Zentralbl Chirurg 125: 494-499.

Babensee JE, McIntire LV, Mikos AG. 2000; Growth factor delivery for tissue engineering. Pharmaceut Res 17: 497-504.

Brittberg M. 1999; Autologous chondrocyte transplantation. Clin Orthop Rel Res S147-155.

Brittberg M, Lindahl A, Nilsson A, et al. 1994; Treatment of deep cartilage defects in the knee with autologous chondrocyte transplantation. N Engl J Med 331: 889-895.

Buckwalter JA. 1998; Articular cartilage: injuries and potential for healing. J Orthop Sports Phys Ther 28: 192-202.

Cancedda R, Dozin B, Giannoni P, et al. 2003; Tissue engineering and cell therapy of cartilage and bone. Matrix Biol 22: 81-91.

Cao T, Ho KH, Teoh SH. 2003; Scaffold design and in vitro study of osteochondral coculture in a three-dimensional porous polycaprolactone scaffold fabricated by fused deposition modelling. Tissue Eng 9: S103-112.

Carranza-Bencano A, Perez-Tinao M, Ballesteros-Vazquez P, et al. 1999; Comparative study of the reconstruction of articular cartilage defects with free costal perichondrial grafts and free tibial periosteal grafts: an experimental study on rabbits. Calcif Tissue Int 65: 402-407.

Chang CH, Lin FH, Lin CC, et al. 2004; Cartilage tissue engineering on the surface of a novel gelatin-calcium-phosphate biphasic scaffold in a double-chamber biorector. J Biomed Mater Res B Appl Biomater 71B: 313-321.

Chen GP, Sato T, Tanaka J, et al. 2006a; Preparation of a biphasic scaffold for osteochondral tissue engineering. Mater Sci Eng C Biomim Supramol Syst 26: 118-123.

Chen GP, Tanaka J, Tateishi T. 2006b; Osteochondral tissue engineering using a PLGA-collagen hybrid mesh. Mater Sci Eng C Biomim Supramol Syst 26: 124-129.

Chen GP, Ushida T, Tateishi T. 2002; Scaffold design for tissue engineering. Macromol Biosci 2: 67-77.

Demarteau O, Jakob M, Schafer D, et al. 2003a; Development and validation of a bioreactor for physical stimulation of engineered cartilage. Biorheology 40: 331-336.

Demarteau O, Wendt D, Braccini A, et al. 2003b; Dynamic compression of cartilage constructs engineered from expanded human articular chondrocytes. Biochem Biophys Res Commun 310: 580-588.

Dounchis JS, Coutts RD, Amiel D. 2000; Cartilage repair with autogenic perichondrium cell/polylactic acid grafts: a two-year study in rabbits. $J$ Orthop Res 18: 512-515.

Erickson GR, Gimble JM, Franklin DM, et al. 2002; Chondrogenic potential of adipose tissue-derived stromal cells in vitro and in vivo. Biochem Biophys Res Commun 290: 763-769.

Evans MJ, Kaufman MH. 1981; Establishment in culture of pluripotential cells from mouse embryos. Nature 292: 154-156.

Felson DT, Zhang YQ. 1998; An update on the epidemiology of knee and hip osteoarthritis with a view to prevention. Arthrit Rheum 41: $1343-1355$.

Frenkel SR, Di Cesare PE. 2004; Scaffolds for articular cartilage repair. Ann Biomed Eng 32: 26-34.

Frenkel SR, Toolan B, Menche D, et al. 1997; Chondrocyte transplantation using a collagen bilayer matrix for cartilage repair. $J$ Bone Joint Surg Br 79B: 831-836.

Galois L, Freyria AM, Grossin L, et al. 2004; Cartilage repair: surgical techniques and tissue engineering using polysaccharide- and collagen-based biomaterials. Biorheology 41: 433-443. 
Gao JZ，Dennis JE，Solchaga LA， et al. 2001; Tissue-engineered fabrication of an osteochondral composite graft using rat bone marrow-derived mesenchymal stem cells. Tissue Eng 7: 363-371.

Gao RZ, Dennis JE, Solchaga LA, et al. 2002; Repair of osteochondral defect with tissue-engineered two-phase composite material of injectable calcium phosphate and hyaluronan sponge. Tissue Eng 8: 827-837.

Ghosh S, Viana JC, Reis RL et al. 2006; Bilayered constructs based on poly(L-lactic acid) and starch for tissue engineering of osteochondral defects. Mat Sci Eng C (in press).

Ghosh S, Viana JC, Reis RL, et al. 2006; Osteochondral tissue engineering constructs with a cartilage part made of poly(L-lactic acid) starch blend and a bioactive poly(L-lactic acid) composite layer for subchondral bone. Bioceramics 18(1-2): 309-311, 1109-1112.

Gillogly SD, Voight M, Blackburn T. 1998; Treatment of articular cartilage defects of the knee with autologous chondrocyte implantation. J Orthop Sports Phys Ther 28: 241-251.

Gimble JM, Guilak F. 2003a; Adipose-derived adult stem cells: isolation, characterization, and differentiation potential. Cytotherapy 5: 362-369.

Gimble JM, Guilak F. 2003b; Differentiation potential of adiposederived adult stem (ADAS) cells. Curr Top Dev Biol 58: 137-160.

Glowacki J. 2000; In vitro engineering of cartilage. J Rehab Res Dev 37: $171-177$.

Gomes ME, Godinho JS, Tchalamov D, et al. 2002; Alternative tissue engineering scaffolds based on starch: processing methodologies, morphology, degradation and mechanical properties. Mater Sci Eng C Biomim Supramol Syst 20: 19-26.

Gomes ME, Reis RL. 2004; Biodegradable polymers and composites in biomedical applications: from catgut to tissue engineering, Part 1. Available systems and their properties. Int Mater Rev 49: 261-273.

Gomes ME, Ribeiro AS, Malafaya PB, et al. 2001; A new approach based on injection moulding to produce biodegradable starch-based polymeric scaffolds: morphology, mechanical and degradation behaviour. Biomaterials 22: 883-889.

Gomes ME, Sikavitsas VI, Behravesh E, et al. 2003; Effect of flow perfusion on the osteogenic differentiation of bone marrow stromal cells cultured on starch-based three-dimensional scaffolds. J Biomed Mater Res A 67A: 87-95.

Grande DA, Breitbart AS, Mason J, et al. 1999; Cartilage tissue engineering: current limitations and solutions. Clin Orthop Rel Res S176-S185.

Gregory CA, Prockop DJ, Spees JL. 2005; Non-hematopoietic bone marrow stem cells: molecular control of expansion and differentiation. Exp Cell Res 306: 330-335.

Guidoin MF, Marois Y, Bejui J, et al. 2000; Analysis of retrieved polymer fibre-based replacements for the ACL. Biomaterials 21: 2461-2474.

Guo XM, Wang CY, Duan CM, et al. 2004; Repair of osteochondral defects with autologous chondrocytes seeded onto bioceramic scaffold in sheep. Tissue Eng 10: 1830-1840.

Halvorsen YDC, Franklin D, Bond AL, et al. 2001; Extracellular matrix mineralization and osteoblast gene expression by human adipose tissue-derived stromal cells. Tissue Eng 7: 729-741.

Hangody L, Kish G, Karpati Z, et al. 1998; Mosaicplasty for the treatment of articular cartilage defects: application in clinical practice. Orthopedics 21: 751-756.

Holland TA, Bodde EWH, Baggett LS, et al. 2005; Osteochondral repair in the rabbit model utilizing bilayered, degradable oligo[poly(ethylene glycol) fumarate] hydrogel scaffolds. J Biomed Mater Res A 75A: 156-167.

Holland TA, Bodde EWH, Cuijpers V, et al. 2007; Degradable hydrogel scaffolds for in vivo delivery of single and dual growth factors in cartilage repair. Osteoarthr Cartilage 15: 187-197.

Holy CE, Shoichet MS, Davies JE. 2000; Engineering threedimensional bone tissue in vitro using biodegradable scaffolds: investigating initial cell-seeding density and culture period. $J$ Biomed Mater Res 51: 376-382.

Huang J, DiSilvio L, Wang M, et al. 1997; In vitro mechanical and biological assessment of hydroxyapatite-reinforced polyethylene composite. J Mater Sci Mater Med 8: 775-779.

Hung CT, Lima EG, Mauck RL, et al. 2003; Anatomically shaped osteochondral constructs for articular cartilage repair. J Biomech 36: $1853-1864$

Hung CT, Mauck RL, Wang CCB, et al. 2004; A paradigm for functional tissue engineering of articular cartilage via applied physiologic deformational loading. Ann Biomed Eng 32: 35-49.
Hunziker EB. 2000; Articular cartilage repair: problems and perspectives. Biorheology 37: 163-164.

Hunziker EB. 2002; Articular cartilage repair: basic science and clinical progress. A review of the current status and prospects. Osteoarthr Cartilage 10: 432-463.

Hutmacher DW. 2000; Scaffolds in tissue engineering bone and cartilage. Biomaterials 21: 2529-2543.

Hutmacher DW, Sittinger M, Risbud MV. 2004; Scaffold-based tissue engineering: rationale for computer-aided design and solid freeform fabrication systems. Trends Biotechnol 22: 354-362.

Jackson RW, Dietrichs C. 2003; The results of arthroscopic lavage and debridement of osteoarthritic knees based on the severity of degeneration: a 4- to 6-year symptomatic follow-up. Arthroscopy $J$ Arthrosc Relat Surg 19: 13-20.

Jadlowiec JA, Celil AB, Hollinger JO. 2003; Bone tissue engineering: recent advances and promising therapeutic agents. Exp Opin Biol Ther 3: 409-423.

Janmey PA, Weitz DA. 2004; Dealing with mechanics: mechanisms of force transduction in cells. Trends Biochem Sci 29: 364-370.

Jorgensen C, Gordeladze J, Noel D. 2004; Tissue engineering through autologous mesenchymal stem cells. Curr Opin Biotechnol 15: 406-410.

Kang SW, Yoon JR, Lee JS, et al. 2006; The use of poly(lactic-coglycolic acid) microspheres as injectable cell carriers for cartilage regeneration in rabbit knees. J Biomater Sci 17: 925-939.

Karageorgiou V, Kaplan D. 2005; Porosity of 3D biomaterial scaffolds and osteogenesis. Biomaterials 26: 5474-5491.

Karp JM, Shoichet MS, Davies JE. 2003; Bone formation on twodimensional (DL-lactide-co-glycolide) (PLGA) films and threedimensional PLGA tissue engineering scaffolds in vitro. J Biomed Mater Res A 64A: 388-396.

Kawanishi M, Ushida T, Kaneko T, et al. 2004; New type of biodegradable porous scaffolds for tissue-engineered articular cartilage. Mater Sci Eng C Biomim Supramol Syst 24: 431-435.

Kim BS, Mooney DJ. 1998; Engineering smooth muscle tissue with a predefined structure. J Biomed Mater Res 41: 322-332.

Kish G, Hangody L. 2004; A prospective, randomised comparison of autologous chondrocyte implantation versus mosaicplasty for osteochondral defects in the knee. J Bone Joint Surg Br 86B: 619-619.

Kisiday JD, Jin MS, DiMicco MA, et al. 2004; Effects of dynamic compressive loading on chondrocyte biosynthesis in selfassembling peptide scaffolds. J Biomech 37: 595-604.

Kreklau B, Sittinger M, Mensing MB, et al. 1999; Tissue engineering of biphasic joint cartilage transplants. Biomaterials 20: 1743-1749.

Kuettner KE, Cole AA. 2005; Cartilage degeneration in different human joints. Osteoarthr Cartilage 13: 93-103.

Langer R. 1999; Selected advances in drug delivery and tissue engineering. J Contr Release 62: 7-11.

Langer R, Vacanti JP. 1993; Tissue engineering. Science 260: 920-926.

Lee CR, Grodzinsky AJ, Spector A. 2003; Biosynthetic response of passaged chondrocytes in a type II collagen scaffold to mechanical compression. J Biomed Mater Res A 64A: 560-569.

Leong KF, Cheah CM, Chua CK. 2003; Solid freeform fabrication of three-dimensional scaffolds for engineering replacement tissues and organs. Biomaterials 24: 2363-2378.

Li P, Bakker D, van Blitterswijk CA. 1997; The bone-bonding polymer Polyactive(R) 80/20 induces hydroxycarbonate apatite formation in vitro. $J$ Biomed Mater Res 34: 79-86.

Li P, Yang Q, Zhang F, et al. 1992; The effect of residual glassy phase in a bioactive glass-ceramic on the formation of its surface apatite layer in vitro. J Mater Sci Mater Med 3: 452-456.

Li XD, Jin L, Balian G, et al. 2006; Demineralized bone matrix gelatin as scaffold for osteochondral tissue engineering. Biomaterials 27: $2426-2433$.

Li Y, Ma T, Yang ST, et al. 2001; Thermal compression and characterization of three-dimensional nonwoven PET matrices as tissue engineering scaffolds. Biomaterials 22: 609-618.

Lima EG, Mauck RL, Han SH, et al. 2004; Functional tissue engineering of chondral and osteochondral constructs. Biorheology 41: $577-590$

Lin HR, Kuo CJ, Yang CY, et al. 2002; Preparation of macroporous biodegradable PLGA scaffolds for cell attachment with the use of mixed salts as porogen additives. J Biomed Mater Res 63: 271-279.

Lipman JM, McDevitt CA, Sokoloff L. 1983; Xenografts of articular chondrocytes in the nude mouse. Calcif Tissue Int 35: 767-772. 
Liu Y, de Groot K, Hunziker EB. 2005; BMP-2 liberated from biomimetic implant coatings induces and sustains direct ossification in an ectopic rat model. Bone 36: 745-757.

Lutolf MR, Weber FE, Schmoekel HG, et al. 2003; Repair of bone defects using synthetic mimetics of collagenous extracellular matrices. Nat Biotechnol 21: 513-518.

Madihally SV, Matthew HWT. 1999; Porous chitosan scaffolds for tissue engineering. Biomaterials 20: 1133-1142.

Mahmoudifar N, Doran PM. 2005a; Tissue engineering of human cartilage and osteochondral composites using recirculation bioreactors. Biomaterials 26: 7012-7024.

Mahmoudifar N, Doran PM. 2005b; Tissue engineering of human cartilage in bioreactors using single and composite cell-seeded scaffolds. Biotechnol Bioeng 91: 338-355.

Malafaya PB, Pedro AJ, Peterbauer A, et al. 2005; Chitosan particles agglomerated scaffolds for cartilage and osteochondral tissue engineering approaches with adipose tissue derived stem cells. J Mater Sci Mater Med 16: 1077-1085.

Mano JF, Silva GA, Azevedo HS et al. Natural origin biodegradable systems on tissue engineering and regenerative medicine: present status and some moving trends. $J$ R Soc Interface (in press).

Mano JF, Sousa RA, Boesel LF, et al. 2004; Bioinert, biodegradable and injectable polymeric matrix composites for hard tissue replacement: state of the art and recent developments. Compos Sci Technol 64: 789-817.

Mao JS, Zhao LG, Yin YJ, et al. 2003; Structure and properties of bilayer chitosan-gelatin scaffolds. Biomaterials 24: 1067-1074.

Martin GR. 1981; Isolation of a pluripotent cell-line from early mouse embryos cultured in medium conditioned by teratocarcinoma stem cells. Proc Natl Acad Sci USA Biol Sci 78: 7634-7638.

Martin I, Muraglia A, Campanile G, et al. 1997; Fibroblast growth factor-2 supports ex vivo expansion and maintenance of osteogenic precursors from human bone marrow. Endocrinology 138: 4456-4462.

Martin I, Wendt D, Heberer M. 2004; The role of bioreactors in tissue engineering. Trends Biotechnol 22: 80-86.

Mikos AG, Bao Y, Cima LG, et al. 1993a; Preparation of poly(glycolic acid) bonded fibre structures for cell attachment and transplantation. J Biomed Mater Res 27: 183-189.

Mikos AG, Sarakinos G, Leite SM, et al. 1993b; Laminated threedimensional biodegradable foams for use in tissue engineering. Biomaterials 14: 323-330.

Mikos AG, Thorsen AJ, Czerwonka LA, et al. 1994; Preparation and characterization of poly(L-lactic acid) foams. Polymer 35: 1068-1077.

Mooney DJ, Baldwin DF, Suh NP, et al. 1996; Novel approach to fabricate porous sponges of poly(D,L-lactic-co-glycolic acid) without the use of organic solvents. Biomaterials 17: 1417-1422.

Morihara T, Harwood F, Goomer R, et al. 2002; Tissue-engineered repair of osteochondral defects: effects of the age of donor cells and host tissue. Tissue Eng 8: 921-929.

Murphy WL, Dennis RG, Kileny JL, et al. 2002; Salt fusion: an approach to improve pore interconnectivity within tissue engineering scaffolds. Tissue Eng 8: 43-52.

Na K, Kim S, Woo DG, et al. 2007; Synergistic effect of TGF $\beta$-3 on chondrogenic differentiation of rabbit chondrocytes in thermoreversible hydrogel constructs blended with hyaluronic acid by in vivo test. J Biotechnol 128: 412-422.

Newman AP. 1998; Articular cartilage repair. Am J Sports Med 26: 309-324.

Niederauer GG, Slivka MA, Leatherbury NC, et al. 2000; Evaluation of multiphase implants for repair of focal osteochondral defects in goats. Biomaterials 21: 2561-2574.

O'Driscoll SW. 1998; The healing and regeneration of articular cartilage. J Bone Joint Surg Am 80A: 1795-1812.

Oliveira AL, Mano JF, Reis RL. 2003; Nature-inspired calcium phosphate coatings: present status and novel advances in the science of mimicry. Curr Opin Solid State Mater Sci 7: 309-318.

Oliveira JM, Rodrigues MT, Silva SS, et al. 2006; Novel hydroxyapatite/chitosan bilayered scaffold for osteochondral tissue-engineering applications: scaffold design and its performance when seeded with goat bone marrow stromal cells. Biomaterials 27: 6123-6137.

Oonishi H. 1991; Orthopedic applications of hydroxyapatite. Biomaterials 12: 171-178.

Pacifici M, Koyama E, Iwamoto M, et al. 2000; Development of articular cartilage: what do we know about it and how may it occur? Connect Tissue Res 41: 175-184.
Park A, Wu B, Griffith LG. 1998; Integration of surface modification and $3 \mathrm{D}$ fabrication techniques to prepare patterned poly(L-lactide) substrates allowing regionally selective cell adhesion. $J$ Biomater Sci 9: 89-110.

Peitl O, LaTorre GP, Hench LL. 1996; Effect of crystallization on apatite-layer formation of bioactive glass 45S5. J Biomed Mater Res 30: 509-514.

Quirk RA, France RM, Shakesheff KM, et al. 2004; Supercritical fluid technologies and tissue engineering scaffolds. Curr Opin Solid State Mater Sci 8: 313-321.

Radin EL, Rose RM. 1986; Role of subchondral bone in the initiation and progression of cartilage damage. Clin Orthop Relat Res 213: 34-40.

Redman SN, Oldfield SF, Archer CW. 2005; Current strategies for articular cartilage repair. Eur Cells Mater 9: 23-32.

Reis RL, Weiner S. 2004; Learning from Nature How to Design New Implantable Biomaterials: From Biomineralization Fundamentals to Biomimetic Materials and Processing Routes. Kluwer Academic: Dordrecht.

Rose FRAJ, Hou QP, Oreffo ROC. 2004; Delivery systems for bone growth factors - the new players in skeletal regeneration. $J$ Pharm Pharmacol 56: 415-427.

Rose FRAJ, Oreffo ROC. 2002; Bone tissue engineering: hope vs. hype. Biochem Biophys Res Commun 292: 1-7.

Salgado AJ, Coutinho OP, Reis RL. 2004; Bone tissue engineering: state of the art and future trends. Macromol Biosci 4: 743-765.

Schaefer D, Martin I, Jundt G, et al. 2002; Tissue-engineered composites for the repair of large osteochondral defects. Arthrit Rheum 46: 2524-2534.

Schaefer D, Martin I, Shastri P, et al. 2000; In vitro generation of osteochondral composites. Biomaterials 21: 2599-2606.

Schek RM, Taboas JM, Segvich SJ, et al. 2004; Engineered osteochondral grafts using biphasic composite solid free-form fabricated scaffolds. Tissue Eng 10: 1376-1385.

Schoof H, Apel J, Heschel I, et al. 2001; Control of pore structure and size in freeze-dried collagen sponges. $J$ Biomed Mater Res 58: 352-357.

Shannon FJ, Devitt AT, Poynton AR, et al. 2001; Short-term benefit of arthroscopic washout in degenerative arthritis of the knee. Int Orthop 25: 242-245.

Shao XX, Hutmacher DW, Ho ST, et al. 2006; Evaluation of a hybrid scaffold/cell construct in repair of high-load-bearing osteochondral defects in rabbits. Biomaterials 27: 1071-1080.

Shapiro F, Koide S, Glimcher MJ. 1993; Cell origin and differentiation in the repair of full-thickness defects of articular cartilage. J Bone Joint Surg Am 75A: 532-553.

Shea LD, Wang D, Franceschi RT, et al. 2000; Engineered bone development from a pre-osteoblast cell line on three-dimensional scaffolds. Tissue Eng 6: 605-617.

Sherwood JK, Riley SL, Palazzolo R, et al. 2002; A three-dimensional osteochondral composite scaffold for articular cartilage repair. Biomaterials 23: 4739-4751.

Shortkroff S, Barone L, Hsu HP, et al. 1996; Healing of chondral and osteochondral defects in a canine model: the role of cultured chondrocytes in regeneration of articular cartilage. Biomaterials 17: $147-154$.

Sikavitsas VI, Temenoff JS, Mikos AG. 2001; Biomaterials and bone mechanotransduction. Biomaterials 22: 2581-2593.

Solchaga LA, Gao JZ, Dennis JE, et al. 2002; Treatment of osteochondral defects with autologous bone marrow in a hyaluronan-based delivery vehicle. Tissue Eng 8: 333-347.

Solchaga LA, Temenoff JS, Gao JZ, et al. 2005; Repair of osteochondral defects with hyaluronan- and polyester-based scaffolds. Osteoarthr Cartil 13: 297-309.

Taguchi T, Sawabe Y, Kobayashi H, et al. 2004; Preparation and characterization of osteochondral scaffold. Mater Sci Eng C Biomim Supramol Syst 24: 881-885.

Temenoff JS, Mikos AG. 2000; Review: tissue engineering for regeneration of articular cartilage. Biomaterials 21: 431-440.

Thomson RC, Wake MC, Yaszemski MJ, et al. 1995a; Biodegradable polymer scaffolds to regenerate organs. Adv Polym Sci 122: 245-274.

Thomson RC, Yaszemski MJ, Powers JM, et al. 1995b; Fabrication of biodegradable polymer scaffolds to engineer trabecular bone. $J$ Biomater Sci 7: 23-38.

Tuan RS, Boland G, Tuli R. 2003; Adult mesenchymal stem cells and cell-based tissue engineering. Arthrit Res Ther 5: 32-45. 
Tuli R, Nandi S, Li WJ, et al. 2004; Human mesenchymal progenitor cell-based tissue engineering of a single-unit osteochondral construct. Tissue Eng 10: 1169-1179.

van der Kooy D, Weiss S. 2000; Why stem cells? Science 287: 1439-1441.

van Susante JLC, Buma P, Homminga GN, et al. 1998; Chondrocyteseeded hydroxyapatite for repair of large articular cartilage defects. A pilot study in the goat. Biomaterials 19: 2367-2374.

Vunjak-Novakovic G, Obradovic B, Martin I, et al. 1998; Dynamic cell seeding of polymer scaffolds for cartilage tissue engineering. Biotechnol Progr 14: 193-202.

Waldman SD, Spiteri CG, Grynpas MD, et al. 2004; Long-term intermittent compressive stimulation improves the composition and mechanical properties of tissue-engineered cartilage. Tissue Eng 10: 1323-1331.

Wang XH, Grogan SP, Rieser F, et al. 2004; Tissue engineering of biphasic cartilage constructs using various biodegradable scaffolds: an in vitro study. Biomaterials 25: 3681-3688.

Washburn NR, Simon CG, Tona A, et al. 2002; Co-extrusion of biocompatible polymers for scaffolds with co-continuous morphology. J Biomed Mater Res 60: 20-29.
Wendt D, Jakob M, Martin I. 2005; Bioreactor-based engineering of osteochondral grafts: from model systems to tissue manufacturing. $J$ Biosci Bioeng 100: 489-494.

Woodfield TBF, Bezemer JM, Pieper JS, et al. 2002; Scaffolds for tissue engineering of cartilage. Crit Rev Eukaryot Gene Expr 12: 209-236.

Woodfield TBF, Malda J, de Wijn J, et al. 2004; Design of porous scaffolds for cartilage tissue engineering using a three-dimensional fibre-deposition technique. Biomaterials 25: 4149-4161.

Yoon JJ, Park TG. 2001; Degradation behaviors of biodegradable macroporous scaffolds prepared by gas foaming of effervescent salts. J Biomed Mater Res 55: 401-408.

Zhang H, Hutmacher DW, Chollet F, et al. 2005; Microrobotics and MEMS-based fabrication techniques for scaffold-based tissue engineering. Macromol Biosci 5: 477-489.

Zuk PA, Zhu M, Ashjian P, et al. 2002; Human adipose tissue is a source of multipotent stem cells. Mol Biol Cell 13: 4279-4295.

Zuk PA, Zhu M, Mizuno H, et al. 2001; Multilineage cells from human adipose tissue: implications for cell-based therapies. Tissue Eng 7: 211-228. 